\title{
12 KEY ROLE PLAYERS IN THE INITIATION AND IMPLEMENTATION OF INTRANET TECHNOLOGY
}

\author{
Rens Scheepers \\ Aalborg University \\ Denmark
}

\begin{abstract}
Internet technologies have opened up vast possibilities for many organizations, including their application purely within the organizational boundary in the form of intranets. However, little is known about the organizational role players in the context of this technology. This paper describes a field study that examines the role players in the initiation and implementation of intranet technology in three large organizations in two countries. Using organizational innovation process theory and available intranet literature, the role players, their roles, their challenges and interrelationships are identified. Five key interrelated roles are isolated: the technology champion, organizational sponsor, intranet coordinator, intranet developer and content provider. Technology champions play the important role of initiating the technology in the organization. The organizational sponsor nurtures and protects the budding technology and its change agents throughout the process. The key role of intranet coordinator features prominently in organization-wide coordination, control and feedback across functional boundaries, while stimulating organizational use and content generation simultaneously. The intranet developer role is crucial for more advanced organizational application of the technology. Finally, the role of content providers is significant in creating a critical mass of content early during implementation to ensure progress.
\end{abstract}

Keywords: Intranet, initiation, implementation, role players, organizational innovation process. 


\section{Introduction}

Internet technologies have opened up vast possibilities in terms of their organizational application. This is not only true for applications with an external focus (e.g., electronic commerce and "extranets" between organizations), but also for applications with an internal focus (e.g., organizational intranets). The latter technology is the focus in this paper.

An intranet is the application of Internet technology, more specifically World Wide Web technology, purely within the organizational boundary. Internet technology (web servers, browsers, etc.) is applied, but access is restricted exclusively to organizational members, for example, by firewalls (Oppliger 1997) or physically separating the intranet from external networks (firebreaks).

The organization's central information technology (IT) group has traditionally been the home of organization-wide information technology. Much of the literature concerning the introduction of organization-wide information technology concerns a paradigm where actors within this group play the key role in implementing technologies to address the needs of various user communities in the organization (e.g., Ginzberg 1981; Kling and Iacono 1984; Lucas, Ginzberg and Schultz 1990; Swanson 1987; Walsham 1993).

Early published research into implementation of intranet technology seems to indicate a shift in this paradigm. Some intranet studies have found that the technology was in fact initiated by decentralized actors outside the IT group (Bhattacherjee 1998; Jarvenpaa and Ives 1996). Lyytinen, Rose and Welke (1998) stress the profound impact of the continuing evolution of Internet (and intranet) computing infrastructure on organizational processes. They predict that the ubiquitous nature of these technologies will blur traditional IS roles (e.g., users will become developers); demand new roles as technologies and media coalesce; and further that these changes will be on a much grander scale than ever before (e.g., as in the case of end user computing).

These early research efforts lead us to expect a new "cast of characters" who may be involved in the initiation and implementation of intranet technology. This paper, therefore, seeks to answer the following questions: who are the key intranet role players and what roles do they play? Moreover, what are the key challenges associated with these roles and how do the roles interrelate?

The paper is structured as follows: The theory of the organizational innovation process is drawn upon to identify key role players. These roles are then examined in the context of available intranet literature. A report on a field study of three intranet cases is made and these cases are analyzed using the innovation process theory and intranet literature. The intranet role players are identified and each role's key challenges and interrelationships are described. Finally, the findings are discussed, conclusions are drawn, and issues for future research indicated.

\section{Role Players in the Organizational Innovation Process}

The initiation and implementation of a new technology within an organization can be regarded as an organizational innovation process (Zaltman, Duncan and Holbek 1973). 
Rogers (1995) describes the organizational innovation process as consisting of two broad activities: initiation and implementation.

Initiation includes the information gathering, conceptualizing, and planning for the adoption of an innovation, leading up to the actual adoption decision. Implementation includes all the events, actions and decisions involved in putting the innovation into use (Rogers 1995, p. 392). In general, a new innovation is initiated and adopted by a small group of actors. However, the implementation of the innovation concerns the communication of the innovation to a much larger group of organizational members who should also adopt and ultimately put the innovation into use (voluntary or involuntary) (Wynekoop and Senn 1992).

A number of role players are recognized in the context of the organizational innovation process. Initiation of an innovation is usually attributed to the efforts of innovators, and often an individual innovator (Schön 1963). In some cases, the innovator actually works outside the formal research teams of organizations, and as a consequence without organizational support. Schön notes that due to the considerable resources needed for organization-wide implementation of an innovation, someone with the required power and prestige in the organization needs to emerge to take control of the innovation, else the process stalls. This role is played by an organizational sponsor (Humphrey 1989; Rogers 1995). Although the sponsor role is also labeled a "champion" by some authors, the term "organizational sponsor" is used here to avoid confusion later on when referring to the literature describing roles in information technology innovations. Once an organizational sponsor has emerged for the innovation, the innovation process can enter the implementation stage. Change agents play an important role when the implementation of an innovation demands changes in the behavior of organizational members. Change agents communicate the innovation to organizational members and seek to influence their behavior with respect to the innovation (Rogers 1995).

In the context of information technology (IT) innovations, the roles of "technology champion" (innovator), organizational sponsor and change agents are also widely recognized. A technology champion is an organizational member who initiates the use of a new information technology in the organization (Beath 1991). Technology champions are sometimes informal experts whose main responsibilities are "doing work" and not to experiment with new technology (Attewell 1992). In many cases, technology champions lack the necessary authority and/or formal resources (Beath 1991) and thus seek to draw the attention of senior management toward the technology (Lawless and Price 1992). A sponsor is usually a senior manager who realizes the potential of the information technology in the organization. She either allocates organizational resources towards further implementation of the technology herself and/or negotiates such resources with her senior colleagues (Martinsons 1993). Once the sponsor has taken "ownership" of the technology, the role of the technology champion disappears into the background (Orlikowski et al. 1995). Beatty and Gordon (1991) describe the role of the organizational sponsor in subsequent implementation stages as that of a "godfather" who empowers and supports agents of this change in the organization.

Implementation of an innovation is an organizational change process and concerns not only the technical, but also the political and cultural dimensions of the change (Keen 1981; Markus 1983; Walsham 1993). Change agents come into play to effect the implementation of a new information technology (Beatty and Gordon 1991; Markus and 
Benjamin 1996; Orlikowski et al. 1995). These agents play a key role in spreading the new information technology to organizational actors. Change agents should be both technically and politically astute and capable of addressing the problems associated with the implementation. Markus and Benjamin describe three models of the change agent role: the traditional model, the facilitator and the advocate model. Simply stated, the traditional model assumes technology causes the change and the change agent has a limited role beyond building the technology. In the facilitator model, the change agent tries to reduce friction between users and technology specialists, thereby enabling better IT management and use. In the advocate model, the change agent attempts to influence people's behavior in particular directions that the change agent views as desirable. Markus and Benjamin note that a likely change agent role description includes elements of all three models.

\section{Available Intranet Literature}

Probably due to the attention in the computer press, intranets have been a "hot" topic and a number of "popular" books have resulted (e.g., Bernard 1996; Dyson, Coleman and Gilbert 1997; Hills 1997). These mostly describe the marvels of intranet technology, how it integrates text, graphics, sound, and video, and the "ease" with which attractive intranet websites can be built. However, in terms of providing insight into intranet implementation, none of these sources go much beyond anecdotal "success stories."

A few published research studies highlight some of the general challenges associated with intranet technology implementation in the organizational context (e.g., Bansler et al. 1999; Goles and Hirschheim 1997; Scheepers and Damsgaard 1997).

Damsgaard and Scheepers (1999a) describe intranet technology as multi-purpose, richly networked and malleable in terms of its application. They isolate a number of intranet technology "use modes." These range from simple uses such as the publishing of home pages, newsletters, technical documents, product catalogues, employee directories, etc., to more advanced uses such as organization-wide searching for information; transacting with functionality on intranet pages and other organizational computer-based information systems (e.g., legacy systems); interacting between individuals and groups in the organization (e.g., via discussion groups, collaborative applications); and possibly even recording the computer-based "organizational memory" (e.g., best practices, business processes). The authors note that unlike many interactive media (Markus 1987) where it is sufficient to attract only a critical mass of users (e.g., e-mail), intranets require a critical mass of both users and content to be pervasive. Intranet implementers are thus faced with a double problem: attracting users and getting them to generate sufficient content. A further complexity is that various levels of intranets can co-exist in the organization, because the technology can be implemented centrally in the organization (as a corporate intranet), but decentralized actors (e.g., in divisions, departments or functional groups) can simultaneously implement "childintranets."

Damsgaard and Scheepers (1999b) warn that three main challenges must be overcome to ensure eventual institutionalization of an intranet, else the technology is bound to stagnate. First, if a sponsor does not nurture the technology it cannot evolve beyond its emergent beginnings. Second, if a critical mass of both users and content 
cannot be reached simultaneously, the intranet will not progress. Finally, if the intranet remains uncontrolled (i.e., "grows wild"), it will be perceived to be useless and therefore users will abandon it.

A few studies refer peripherally to other role players during the initiation or later during implementation of intranet technology, but none of these studies go into much depth regarding these roles.

Jarvenpaa and Ives found that the introduction of Web technology was neither initiated by the organization's IT group or by senior management. In the organizations they studied, the technology was initiated by decentralized technology champions from a variety of organizational functions outside the IT group. These champions cooperated as "virtual teams" of "volunteers." The IT groups of the organizations eventually became involved with the technology, but very much in a reactive fashion.

Romm and Wong (1998) describe the implementation of an intranet in an Australian university setting. In contrast to the findings of the Jarvenpaa and Ives research, in their study the intranet was led by the IT department, with a high involvement of senior management. An intranet committee was formed and the project coordinator attempted to convince university departments to add their information to the intranet. Despite his efforts, the intranet was unsuccessful because departments did not live up to their promises of converting and adding content to the intranet.

Bhattacherjee reports on a case study of the "Global Village" project, which describes the implementation of the intranet at US West Communications. The intranet project was initiated by the Finance organization within US West. The Vice President of Finance acted as organizational sponsor and hired a project manager who was a "technological visionary" to implement the intranet. Together with staff within the Finance group, these actors comprised the intranet project group and successfully managed to establish company-wide interest for the intranet. The study reports that "ownership" of intranet content was transferred to individuals in various user departments of the organization.

In a speculative paper, Lyytinen, Rose and Welke predict that the ubiquitous nature of Internet technologies will blur traditional IT roles (e.g., users will become developers) and that we will see new organizational roles as technologies and media design coalesce. They foresee roles of artists and content creators becoming increasingly important and highlight the role of system developers who should be even more capable of cooperating in multi-skilled teams.

\section{Field Study}

The case study research approach is especially appropriate in new topic areas (Eisenhardt 1989). The field study reported here was based on the explorative multi-site longitudinal case study approach (Yin 1989).

Empirical research was conducted in the head office environments of two large organizations in South Africa and one in Denmark. In South Africa, the corporate intranets of the CSIR (www.csir.co.za), a large semi-government R\&D organization, and that of Telkom (www.telkom.co.za), the national telecommunications provider, were studied. In Denmark, the intranet at the headquarters of the LEGO Group (www.lego.com), a global toy manufacturer, was studied. Qualitative data was collected 
from a variety of actors who were involved in the implementation of the technology in these organizations (principle of multiple interpretations, Klein and Myers 1999).

After gaining initial access to the organization, the intranet role players were identified on a peer-referral basis (Howell and Higgins 1990) and interviewed. The aim was to isolate intranet "roles" (Rogers 1995) rather than to identify specific individuals involved in the intranet. Given the duration of this research, this approach allowed us to overcome the problems of variation in position descriptions, new appointments, resignations, etc.

The study aimed to use a flexible data gathering strategy and to find a representative set of data (Benbasat, Goldstein, and Mead 1987). Semi-structured interviews were the primary data collection method used. Open-ended questions were organized into an initial questionnaire using theoretical constructs from the literature and similar research efforts. The initial questionnaire was used in a pilot study and was subsequently refined to improve understandability and comprehension. The refined questionnaire was used for the main data gathering.

The interview guide was used as a basis, but the interview was allowed to digress if other interesting issues surfaced. Interviews also covered normal background information about the size and type of business and about the affiliations and education of the interviewee, etc. All interviews were tape-recorded and notes were taken during the interviews. Other data were also collected, including notes from informal discussions, e-mails, policies, reports, demonstrations, own inspection of the intranet, and even promotional material that was used during some implementations. Interviews were transcribed and shared with the interviewees to check for possible errors and omissions and to evaluate the validity of the interpretation of their "story" (Klein and Myers 1999). Based on all the data and transcripts, rich descriptions of the roles of the various role players were obtained at each site.

Table 1 summarizes the research duration and number of interviews at each site. In two of the cases, apart from an initial "baseline" round of interviews, follow-up interviews were done, mostly with the same interviewees.

\section{Table 1. Summary of Data Collection}

\begin{tabular}{lll}
\hline Organization & Research duration & $\begin{array}{l}\text { Number of Inter- } \\
\text { views }\end{array}$ \\
\hline CSIR Corporate, & September 1997 (pilot); December & 3 (pilot) \\
South Africa & $\begin{array}{l}\text { 1997-January 1998 (baseline); } \\
\text { November 1998 (follow-up) }\end{array}$ & 8 (follow-up) \\
\hline Telkom Head Office, & December 1997-January 1998 & 5 (baseline) \\
South Africa & (baseline); November 1998 (follow- & 4 (follow-up) \\
& up) & \\
\hline LEGO Group Head- & August 1998 and October 1998 & 8 (baseline) \\
quarters, Denmark & (baseline) & \\
\hline
\end{tabular}




\section{Three Cases of Intranet Initiation and Implementation}

\subsection{The CSIR IntraWEB}

The CSIR in South Africa is Africa's largest scientific and technological research, development and implementation organization. It is semi-governmental and does industrial contract research in the public and private sectors in specialized technological areas. The CSIR consists of nine semi-autonomous divisions that report to a president at the head office. In September 1996, the organization started to implement a corporate intranet called the CSIR IntraWEB.

Prior to the implementation of the corporate intranet, computer scientists in a few of the divisions started independent intranet experiments within their environments. Their enthusiasm spread informally to more of the divisions and also to the organization's central Computing Services group. Technical staff in the Computing Services group started constructing an experimental organizational intranet home page. The home page effort gained the support of managers in the Computing Services group and a project leader was appointed within the Computing Services group to take the idea further. The intranet project leader headed up a small team of programmers.

These efforts came to the attention of the CSIR's Vice President of Policy and Technology. The Vice President realized the organization-wide potential of the technology and played a key role in approving funding toward the initiative. The Vice President appointed a Quality and Systems manager with one of her tasks to coordinate the CSIR intranet in conjunction with the intranet project leader at Computing Services. She commented on her role in the implementation:

\section{The Vice President sees me as a custodian...not to do the work, but to coordinate and see that it is done. In other words, to manage the resources.}

Development of the intranet progressed further in the organization and it became known as the CSIR IntraWEB. The Quality and Systems manager formed a steering group consisting of divisional intranet representatives and the intranet project leader. Together with the steering group, she initiated a number of organization-wide initiatives to further awareness of the intranet. This included a major organizational campaign with intranet posters being put up throughout the CSIR, giving away coffee cup "coasters" with the intranet information on them, intranet talks and an intranet "treasure hunt" with prizes to be won. The Vice President remained firmly supportive throughout these efforts, also in convincing his executive colleagues of the organizational advantages of the technology.

The Quality and Systems manager initiated a project via which divisional and corporate business plans, policies, management models and quality plans were put on the intranet. Given the semi-autonomous nature of the divisions, she mentioned this required considerable "lobbying" of some divisional managers.

The intranet project leader initiated a number of developments to integrate existing computer-based systems in the CSIR with the intranet. These included "web-enabling" many of the existing information systems in the CSIR to allow access from the intranet and also new intranet applications such an employee directory, which would combine 
data from a number of systems (e.g., human resources, security access system, etc.). In many cases, this necessitated the project leader to intervene to convince staff in other corporate units to tailor their developments and processes to allow for integration with the intranet. The project leader also initiated the implementation of an intranet search engine to allow organization-wide searches.

Follow-up research after 10 months revealed that after the initial intranet efforts, many divisions and corporate units had subsequently designated specific staff members to take responsibility for the content of their local intranet sites. This created the need for intranet design courses, which were set up by the Quality and Systems manager. Following these courses, a staff member located in the Communications unit created a fairly sophisticated intranet site that automated and improved the previous process by which staff members ordered corporate gifts for their clients. The editor of the staff magazine started to publish the magazine also via the intranet and she was trying to persuade her superior to suspend paper publication altogether.

The intranet project leader held responsibility mainly for the corporate part of the intranet and for the integration of even more organizational systems with the intranet. He described his role further:

[W] are moving towards a development model where my team and I will be responsible for intranet project management. Some development can take place in the divisions, but we will ensure a coordinated approach.

The Quality and Systems manager retired, but the Vice President transferred her role to a senior manager in the newly created CIO office. The CIO manager established a CSIR "Web Council" with senior representatives from all divisions to decide on issues such as content standards, use policies and future directions of the CSIR's intranet and Internet applications.

\subsection{Telkom Intranet}

Telkom South Africa is a government owned company that provides around $40 \%$ of all telephone services on the African continent. The organization consists of a head office, service groups and regional offices in all the main centers of southern Africa. Within Telkom, several individuals in service groups (mainly IT-related environments) and the regional offices were "playing" with pilot intranet sites. These started spreading through informal networks and a large number of "island" sites resulted. A regional technician who created one such pilot site commented:

I'm not "officially" supposed to be involved with the intranet. I just started using it to make my job easier. They can say to me tomorrow to leave it and focus on what I'm supposed to do.

He added: 
People are joking with me, but I put my name on all the intranet pages I create. I want to go further and get a post as a programmer so I can have a budget for software.

These efforts prompted Telkom's Information Executive to establish a small team of four staff members within the IT Services Group and tasked them with the responsibility of integrating the "island" intranets into a cohesive whole. This marked the "formal" start of Telkom's corporate intranet (Damsgaard and Scheepers 1999a) in February 1997.

The intranet team consisted of an information specialist, a graphics designer, a web developer and a network security expert. The team implemented a basic corporate intranet and hyperlinked the unit level intranets to it. The main feature of the corporate intranet was structured "content book" pages of information topics with hyperlinks to the intranet sites throughout Telkom. The team structured the topics and maintained the hyperlinks on an ongoing basis. The "content book" became the primary mechanism for locating information on the intranet (no central search engine existed). Over time, forums for interaction on a variety of organizational issues were added. Many intranet sites, however, still contained IT related information.

Although the Information Executive actively supported the implementation, not all of his senior colleagues were sold on the concept initially. The Information Specialist commented:

At the moment top management is a little bit weary of this new thing. They've got this idea that surfing the intranet means playing around all day. "You are going to surf pornographic sites, you are going to play games." We have to get it across to them that it is of business value to them. We are not at the point where management is giving it their full support.

The Information Executive commissioned a draft intranet policy for Telkom. The policy recommended, among other things, "proper use" of the technology and content standards.

Apart from playing the main role in structuring the content of the corporate intranet, the Information Specialist embarked on a variety of tactics to further intranet use. She featured a monthly "best intranet site" on the corporate intranet; she initiated the distribution of information about the intranet along with employees' pay slips and she launched an intranet poster campaign. As a result, many organizational units started to develop their own intranet presence. These ranged from sites that were very rich in information content to some which a senior manager described as merely "this is me and this is my team" sites.

Follow-up research after 10 months revealed no significant new developments. The Information Executive largely withdrew from the intranet initiative due to organizational demands for his leadership in addressing the Year 2000 problem. Use of the intranet was still mainly for publication and interaction, although the need for more advanced uses, especially transacting with organizational databases, was identified. The task of maintaining the content of intranet sites was seen as an "add-on" to staff members' existing jobs. The Information Specialist started to quality assure the content of intranet 
sites. In a few cases, she removed links from the "content book" to sites which contained outdated information or did not meet the content standards.

\subsection{LEGO Web}

The international LEGO Group, in which the original company was established in 1932, is one of the world's largest toy manufacturers. The LEGO Group is owned and managed by the Kirk Kristiansen family in Denmark. The organization provides creative experiences, construction toys, educational materials, lifestyle products, family parks and media products for children all over the world.

Following the development of the LEGO Group's Internet site, the programmer who was involved in the project, in conjunction with his superior, initiated the idea of an intranet to senior management. A director of the LEGO Group approved a one-man project (the same programmer) and an intranet demonstration prototype was built. The prototype was demonstrated to top management who approved further development. The demonstration happened to coincide with the earlier launch of a new management strategy in the LEGO Group that aimed, among other things, to improve interdepartmental communication. The potential of the intranet technology supporting this management strategy was quickly realized.

Implementation of the envisioned intranet (called LEGO Web) started toward the end of 1996 and early 1997. With strong support from the LEGO Group director, a small team of four programmers was established within the IT group. The LEGO Web project leader headed this team. The Director further appointed a Web editor in the Information and Public Relations department. The intranet project leader and the Web editor cooperated closely. Throughout the implementation, the director ensured adequate funding was available for intranet developments.

Considerable intranet functionality was developed by the intranet project team. This included organizational wide search facilities, a number of organization-wide intranet applications (e.g., a global employee directory integrating e-mail, phone numbers, picture of employee) and facilities for interaction (e.g., intranet discussion groups). Although direct transacting with existing systems was not possible at the time of this research, functionality was built to "upload" information from various systems (e.g., manufacturing data, product information). This allowed for high quality graphical content (e.g., pictures of products and packaging).

Once the basic intranet infrastructure was in place, a decision was made to formally designate about 80 employees worldwide as dedicated LEGO Web "content providers." The Corporate IT Manager reflected on this decision:

[W] are talking about the "hen and the egg" problem. We had to get critical mass here, otherwise people would say "this is nice, but there's nothing on it."

The Web editor controlled the addition of new content to the intranet. She formulated content standards for intranet pages and assured the quality of all intranet content received from content providers prior to its addition to the intranet. The Web 
editor supported the content providers (e.g. in terms of training and the use of content standards).

The Web editor promoted the intranet via a number of articles in the staff newsletter. There was also a formal launch of the intranet attended by the CEO of the LEGO Group. The Web editor engaged in interdepartmental information exchanges such as to convince department $\mathrm{A}$ that they should provide content on the intranet for department B to use. This proved difficult in some cases and she complained of a lack of middle management participation and a tendency that some departments were advertising themselves rather than providing useful information.

The development of the organization-wide employee directory required telephone data to be available more regularly and in an electronic format. This required process changes in the department responsible for the previously printed version of the telephone directory. The intranet project leader intervened to convince this department to convert their paper process to an electronic process so this data could be used on the intranet. Reflecting on her responsibilities, the intranet project leader mentioned she struggled to deliver on existing requirements while "keeping pace" with the rapid new developments in intranet technology.

The newly designated content providers were pleased with their new responsibilities and saw their new task as an upgrade of their work. This was echoed in the following statement:

As secretary, you usually just type what other people think. Now all of a sudden I have an identity of my own. I have got the right to contact [people] with information, instead of going through somebody else.

Though the intranet was well supported by management, some content providers needed to change old ways of doing things in their local units:

We were working with paper before. Here we have a good opportunity to make it cheaper for the company. The user can always be sure they are working with the right version and they can have direct access to it. In my environment, I'm the one that's pushing the intranet.

\section{Analysis of the Cases}

Following the principle of abstraction and generalization (Klein and Myers 1999; Walsham 1993), the theory of the organizational innovation process as well as the available intranet literature are drawn upon and a number of abstract roles in the initiation and implementation of the technology are identified and analyzed. A summary of the identified roles in terms of role descriptions, key challenges and interrelationships appears in Table 2. 







\subsection{Technology Champions}

The role played by intranet technology champions can be identified in all three cases. In the LEGO Web case, the intranet technology champion was an individual programmer who championed the intranet concept based on his earlier involvement in the development of the organization's Internet site. In the CSIR case, the various divisional computer scientists were the technology champions. In the Telkom case, the technology champion role was played by regional technicians and also IS staff in various head office units. In both these cases, the champions interacted and learned from each other's independent experiments via informal peer interaction.

Even though the same technology which is used on the Internet is also used for intranets, technology champions "reinvented" the technology (Attewell 1992) and established the intranet concept in the organizations. The technology champion(s) would then attempt to "sell" the concept to senior management through pilot applications (LEGO Web and Telkom cases) which could demonstrate the technology's potential.

In all cases, the efforts of the technology champions were unsolicited. In no case was senior management found to have initiated the intranet. However, it seems in all cases that the champions had the freedom to experiment with the technology. The motives of intranet technology champions seem to vary (e.g., curiosity, even selfinterest).

In the LEGO Web case, the technology champion was actually within the IT group (as found by Romm and Wong), but as the other two cases demonstrate, technology champions operated independently and outside of the IT group (as found by Bhattacherjee and by Jarvenpaa and Ives).

As predicted by Orlikowski et al., in all of the cases, the technology champion role disappeared into the background once an organizational sponsor and subsequent implementation agents came onto the scene. However, as the Telkom case shows, many of the original IT content sites remained active and it seems some technology champions switched roles afterward and became content providers.

\subsection{Organizational Sponsor}

In all three cases, an organizational sponsor emerged to "take ownership" of the intranet technology. In the CSIR case, the sponsor was the Vice President of Policy and Technology. At Telkom, the sponsor was the Information Executive, while in the LEGO Web case the Group Director played this role.

In all of the cases, an organizational sponsor effectively "grabbed" the intranet concept from the technology champion(s) (Damsgaard and Scheepers 1999b). Although in each of the cases a number of decentralized "child-intranets" co-existed, the intranet sponsor role was invariably played by a single key individual in the organization. In all cases, the sponsor was a senior manager who realized the technology's organizational potential (based on the "selling" efforts of the technology champion(s)). As the Telkom case demonstrated, not all senior managers were sold on the intranet concept initially. This means that the role of the sponsor can involve political risk-taking.

In all cases, the sponsor played an active role in allocating or negotiating funding and resources toward intranet implementation. The sponsor also engaged change agents 
(such as intranet coordinators and developers) to lead organizational implementation of the intranet. It is interesting to note that, in all three cases, the sponsor personally appointed the intranet coordinator.

In subsequent phases, the sponsor did in fact play the "godfather" role (as described by Beatty and Gordon), especially in terms of supporting the intranet agents (CSIR, LEGO Web cases). The sponsor was also instrumental in approving use policies and content standards (LEGO Web and Telkom cases). As the Telkom case shows, a problem may result if the sponsor prematurely withdraws his sponsorship. This may mean that the agents depending on his support may well be left vulnerable (as found by Beatty and Gordon).

\subsection{Intranet Coordinator}

The prominent role of intranet coordinator is identified in all three cases. The intranet coordinator played a central role in the implementation process and was invariably highly visible, but strongly dependent on support of the sponsor. In the CSIR case, the manager of Quality and Systems played this role initially and the role was later continued by the manager in the CIO office. In the Telkom case, the Information Specialist in the IT group played the role, while in the LEGO Web case, the Web editor located in the Information and Public Relations Department played the role. In all cases, the intranet coordinator was located in a central position in the organization.

The cases describe the intranet coordinator as a powerful change agent and the role has strong facilitating and advocating facets (as described by Markus and Benjamin). The focus of the coordinator's role is organization-wide, transcending functional boundaries and the "integrating mechanism" of various intranet activities in the organization. The coordinator was observed to be very much dependent on the organizational sponsor for political support (as in other studies, e.g., Beatty and Gordon). However, in the present cases, the coordinator role was found to be much more prominent than in earlier studies (e.g., Romm and Wong).

The key challenge of the intranet coordinator is to influence the behavior of various organizational actors to change with respect to the new technology. This meant positioning the intranet as a new medium to carry organizational information and making organizational actors with a need for such information aware of the intranet, thereby addressing the "double problem" of reaching a critical mass of both users and content simultaneously (Damsgaard and Scheepers 1999a). In terms of advocating intranet use, various approaches by the coordinator were seen in the cases, e.g., organization-wide campaigns, presentations, articles in staff newspapers, and intranet treasure hunts. In the CSIR and LEGO Web cases, in order to ensure a critical mass of useful content, the coordinator was seen to facilitate cross-functional, intranet initiatives such as the creation of an organization-wide employee directory (in conjunction with the intranet developer). She would support intranet content providers and lobby middle managers (LEGO Web case). In the CSIR and LEGO Web cases, the coordinator was seen as intervening as an "information broker" between departments, convincing them to exchange information via the intranet rather than via traditional means. The coordinator also played a central role in formulating use policies, information standards, and quality assurance of content (Telkom, LEGO Web cases). 


\subsection{Intranet Developer}

In the cases, the role of an intranet developer can also be identified. In the CSIR case, the role was played by the Intranet Project Leader and, in the LEGO case, the role was played by the LEGO Web Project Leader. In the Telkom case, the role of intranet developer as defined here was largely absent.

The role of the intranet developer encompasses the main responsibility for the technical intranet infrastructure developments. The intranet developer is also a powerful change agent who has the ability to intervene where the technical intranet infrastructure requires new systems, changes to existing systems or organizational processes (CSIR, LEGO Web cases). In the CSIR and LEGO Web cases, this role was typically played by a senior project manager within the organization's corporate IT group, but with political backing by the organizational sponsor.

Although in some cases the organization's corporate IT group "reacted" to the intranet initiation by outside technology champions, the intranet developer role later became crucial in leading developments associated with the more advanced technology uses such as searching (e.g., implementing organizational search engines) and transacting (building links to "legacy" systems and integrating existing organizational databases with the intranet).

As witnessed in the LEGO Web case, the intranet developer role also has aspects of a change agent. In this case, the developer intervened to get departments to alter their departmental processes and systems to allow the creation of organization-wide intranet applications (such as the organizational employee directory). In the CSIR and LEGO Web cases, the intranet developer worked in close collaboration with the intranet coordinator, and was also strongly dependent on the sponsor for political support and funding for developments.

The absence of the intranet developer role in Telkom explains the limited use of the technology (only publication and interaction). No organizational search facilities were available, and the intranet coordinator had to resort to "simulating" this functionality manually via the "content book." The need for the developer role was, however, realized in this case.

Although in the CSIR and LEGO Web cases small teams accomplished intranet technical developments, the key role played by the intranet developer personally was well recognized by interviewees. However, as compared to the highly visible role of the intranet coordinator, the role of the intranet developer can be seen as the "second fiddle."

The LEGO Web case demonstrates the impact of rapid new developments in the technology on the intranet developer role, where the interviewee described her struggle between delivering on requirements and "keeping pace" with new technological developments.

\subsection{Content Providers}

The role played by content providers (Bhattacherjee 1998) was identified in all cases. In the Telkom case, these roles were not formalized. In the LEGO Web case, the content provider role was formalized up-front, while formalization of the role happened later in the CSIR case. 


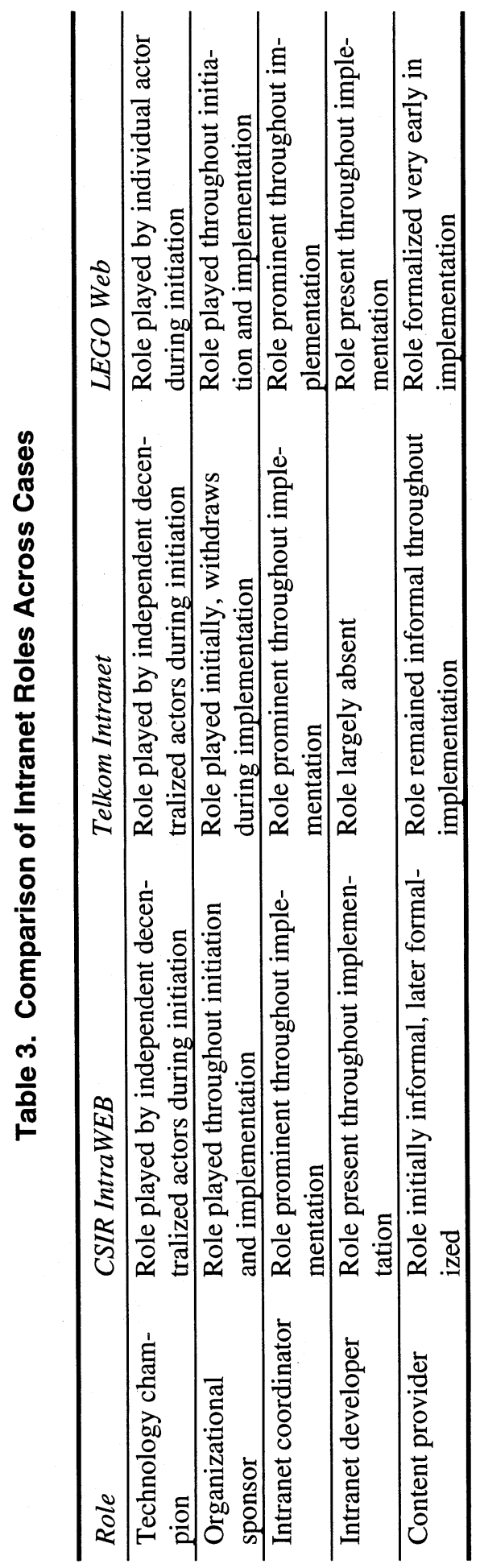


The content provider plays a role of creating and maintaining new intranet content and converting existing information to the intranet at the local unit level, usually on behalf of other colleagues in the unit. However, as is evident in the LEGO Web and CSIR cases, this role extends beyond the pure technology dimension only (Markus and Benjamin 1996). In these cases, the finding was that content providers would operate as local change agents within their own units, advocating more use of the intranet in local processes, and trying to influence their colleagues' behavior.

In the CSIR case, a content provider was observed initiating a fairly advanced process automating the ordering of corporate gifts. Here is an example where the technology blurs roles, because a normal office worker with minimal training was able to develop the kind of functionality one may expect from a "systems developer" (Lyytinen, Rose and Welke 1998). Furthermore, as predicted by Lyytinen, Rose and Welke, in the Telkom and CSIR cases, the intranet technology was seen as creating a need for content providers with artistic or design skills.

As is evident from the Telkom and LEGO Web cases, the key challenges the content provider faces are the design of appropriate content and dealing with their colleagues' resistance to change. In this regard, content providers are dependent on the intranet coordinator for direct support, but also dependent on "indirect" support from the organizational sponsor.

In the LEGO Web case, the comment from the content provider about gaining her "own identity" gives us a rare glimpse at the often intangible potential of the technology in "empowering" workers (Clement 1994).

\section{Discussion}

The discussion is divided in two parts. First, the power of organizational innovation process theory in identifying the intranet role players is reflected upon. Second, the significance of the identified roles is discussed and compared across the cases.

Using the theory of the organizational innovation process with its associated role players has been a useful "theoretical lens" to identify role players in the intranet context. In each case, the roles predicted by the theory could easily be found and the way in which these roles manifested during initiation and implementation could be examined. The theory did, however, limit the study to only identifying roles during implementation where intranet agents attempted to influence, change and stabilize new behavior patterns of fellow actors in the organization. The theory would be inappropriate to identify roles in subsequent routinized use stages where there is less emphasis on "change."

The analysis indicated that, in the case of intranet technology as an interactive medium, the clear demarcation between the "implementation" stage and subsequent "use" stage (Lucas, Ginzberg and Schultz 1990) becomes blurred. Since the interactive medium's implementation success depends on a critical mass of early content to draw users, this moves the role of "users" such as content providers to within the implementation stage itself.

The roles identified here each have their own specific significance. A cross-case comparison of the roles appears in Table 3. 
Technology champions played the important role of initiating the technology in the organizations. As also found by Jarvenpaa and Ives, it was noted that the senior management did not commission the intranet in any of these cases. It was the unsolicited efforts of technology champions that prompted implementation of the technology.

The role of organizational sponsor was significant in all of the cases. Since senior management "did not ask" for the intranet, this role was found to be especially significant in nurturing and protecting the budding technology and its agents throughout the process. Withdrawal of the sponsor during the implementation process seemed to jeopardize the implementation process in one case.

The role of intranet coordinator featured prominently in all of the cases. The role was significant in the sense of providing an organizational wide coordination, control (Ashby 1956) and feedback mechanism (Beer 1959) across functional boundaries while addressing the double problem of stimulating organizational use and content generation simultaneously.

The role of intranet developer was significant when more advanced organizational application of the technology was needed. The absence of this role in one case was seen as restricting the organization to only elementary use modes.

Finally, the role played by content providers seems significant in creating a critical mass of content early in the process to ensure progress. It was interesting to compare the effect of different approaches in terms of when (and if) the organizations decided to formalize this role. It seems that more accelerated intranet implementation depends on early formalization of this role.

Some of the intranet literature has highlighted the significance of intranet steering groups and teams (e.g., Jarvenpaa and Ives 1996; Romm and Wong 1998). However, as found in the present cases, although there was mention of steering groups and intranet teams, the individual role players were the main driving forces in the process.

\section{Conclusion}

The conclusion is that there are five key interrelated roles in the initiation and implementation of intranet technology. As predicted by the innovation process theory and intranet literature, the role of technology champion and organizational sponsor during intranet initiation are identified. During implementation, the technology champion role disappears into the background. The organizational sponsor takes ownership of the technology and empowers and supports three specific change agent roles: the intranet coordinator, intranet developer and content provider.

As predicted by Lyytinen, Rose and Welke, evidence was found that the traditional IS roles of "user" and "developer" are indeed blurred in the case of intranet technology. Some intranet content providers can be seen as "users," and also as "developers" of content and functionality.

Evidence was found that, in the case of intranet technology initiation and implementation, some limelight is stolen from the organization's central IT group (also observed by Jarvenpaa and Ives and by Bhattacherjee). Leading roles were played by technology champions, the organizational sponsor, the intranet coordinator and content 
providers who often resided outside the central IT group. However, it is concluded that the key role of intranet developer (mostly located within the IT group) remains crucial for more advanced organizational application of the technology.

The study has a number of limitations. First, only the initiation and implementation of intranet technology in large, established, and hierarchical organizations were examined. The roles identified and explored here may manifest themselves differently in other settings. For example, in small or medium sized enterprises, one may find that different roles may need to be played by the same individual actor. Furthermore, the study was limited in the sense that it only focused on the initiation and implementation stages. The data did not allow examination of subsequent stages of routinized use of the technology (Rogers 1995) where some authors have speculated about roles such as knowledge managers (Damsgaard and Scheepers 1999b).

Intranet technologies have a very large range of application environments. Fruitful areas for future research include the verification of the roles identified here in more cases, perhaps in different types of organizations (e.g., those in non-profit sectors) and also in different cultures. A further research avenue is to examine new and changed roles once the technology becomes routinized in the organization.

\section{References}

Ashby, W. R. An Introduction to Cybernetics. London: Chapman and Hall, Ltd., 1956.

Attewell, P. "Technology Diffusion and Organizational Learning: The Case of Business Computing,"'Organization Science (3:1), February 1992, pp. 1-19.

Bansler, J. P.; Havn, E.; Thommesen, J.; Damsgaard, J.; and Scheepers, R. "Corporate Intranet Implementation: Managing Emergent Technologies and Organizational Practices," in Proceedings of the Seventh European Conference on Information Systems, J. Pries-Heje, C. U. Ciborra, K. Kautz, J. Valor, E. Christiaanse, and D. Avison (eds.). Copenhagen, Denmark, June 23-25, 1999.

Beath, C. M. " "Supporting the Information Technology Champion," MIS Quarterly, September 1991, pp. 355-371.

Beatty, C. A.; and Gordon, J. R. M. "Preaching the Gospel: the Evangelists of New Technology," California Management Review (33:3), 1991, pp. 73-94.

Beer, S. Cybernetics and Management, $2^{\text {nd }}$ ed. London: The English University Press Ltd., 1959. Benbasat, I.; Goldstein, D. K.; and Mead, M. "The Case Research Strategy in Studies of Information Systems," MIS Quarterly (11:3), September 1987, pp. 369-386.

Bernard, R. The Corporate Intranet. New York: Wiley \& Sons, 1996.

Bhattacherjee, A. "Management of Emerging Technologies: Experiences and Lessons Learned at US West," Information and Management (33), 1998, pp. 263-272.

Clement, A. "Computing at Work: Empowering Action by 'low-level users'," Communications of the ACM (37:1), January 1994, pp. 53-105.

Damsgaard, J., and Scheepers, R. "Power, Influence and Intranet Implementation: A Safari of South African Organizations," Information, Technology and People, 1999a (forthcoming).

Damsgaard, J. and Scheepers, R. "A Stage Model of Intranet Technology Implementation and Management," in Proceedings of the Seventh European Conference on Information Systems, 
J. Pries-Heje, C. U. Ciborra, K. Kautz, J. Valor, E. Christiaanse, and D. Avison (eds.). Copenhagen, Denmark, June 23-25, $1999 \mathrm{~b}$.

Dyson, P.; Coleman, P.; and Gilbert, L. The ABCs of Intranets. San Francisco: Sybex, Inc., 1997. Eisenhardt, K. M. "Building Theories from Case Study Research," Academy of Management Review (14:4), 1989, pp. 532-550.

Ginzberg, M. J. “Key Recurrent Issues in the MIS Implementation Process,” MIS Quarterly, June 1981, pp. 47-59.

Goles, T., and Hirschheim, R. (eds.). Intranets: The Next IS Solution? Houston, TX: Information Systems Research Center, College of Business Administration, University of Houston, 1997.

Hills, M. Intranet Business Strategies. New York: Wiley \& Sons, 1997.

Howell, J. M., and Higgins, C. A. "Champions of Technological Innovation," Administrative Science Quarterly (35), 1990, pp. 317-341.

Humphrey, W. S. Managing the Software Process. Reading, MA: Addison-Wesley Publishing Company, 1989.

Jarvenpaa, S. L., and Ives, B. "Introducing Transformational Information Technologies: The Case of the World Wide Web Technology," International Journal of Electronic Commerce (1:1), 1996, pp. 95-126.

Keen, P. G. W. "Information Systems and Organizational Change," Communications of the ACM (24:1), 1981, pp. 24-33.

Klein, H. K., and Myers, M. D. "A Set of Principles for Conducting and Evaluating Interpretive Field Studies in Information Systems," MIS Quarterly (23:1), March 1999, pp. 67-92.

Kling, R., and Iacono, S. "The Control of Information Systems Developments after Implementation," Communications of the ACM (27:12), December 1984, pp. 1218-1226.

Lawless, M. W., and Price, L. L. "An Agency Perspective on New Technology Champions," Organization Science (3:3), 1992, pp. 342-355.

Lucas, H. C.; Ginżberg, M. J.; and Schultz, R. L. Information Systems Implementation: Testing a Structural Model. Norwood, NJ: Ablex Publishing Corporation, 1990.

Lyytinen, K.; Rose, G.; and Welke, R. "The Brave New World of Development in the Internetwork Computing Architecture (InterNCA) or How Distributed Computing Platforms Will Change Systems Development," Information Systems Journal (8), 1998, pp. 241-253.

Markus, M. L. "Power, Politics, and MIS Implementation," Communications of the ACM (26:6), June 1983, pp. 430-444.

Markus, M. L. "Toward a 'Critical Mass' Theory of Interactive Media: Universal Access, Interdependence and Diffusion,” Communication Research (14:5), 1987, pp. 491-511.

Markus, M. L., and Benjamin, R. I. "Change Agentry: The Next IS Frontier," MIS Quarterly, December 1996, pp. 385-407.

Martinsons, M. G. "Cultivating the Champions for Strategic Information Systems," Journal of Systems Management, August 1993, pp. 31-34.

Oppliger, R. "Internet Security: Firewalls and Beyond," Communications of the ACM (40:5), May 1997, pp. 92-102.

Orlikowski, W. J.; Yates, J.; Okamura, K.; and Fujimoto, M. "Shaping Electronic Communication: The Metastructuring of Technology in the Context of Use," Organization Science (6:4), 1995, pp. 423-444.

Rogers, E. M. Diffusion of Innovations, $4^{\text {th }}$ ed. New York: The Free Press, 1995.

Romm, C. T., and Wong, J. "The Dynamics of Establishing Organizational Web Sites: Some Puzzling Findings," Australian Journal of Information Systems (5:2), 1998, pp. 60-68. 
Scheepers, R., and Damsgaard, J. "Using Internet Technology Within the Organization: A Structurational Analysis of Intranets," in Proceedings of GROUP'97 Conference of Supporting Group Work, S. C. Hayne and W. Prinz (eds.), Phoenix, AZ, Association for Computing Machinery, November 16-19, 1997, pp. 9-18.

Schön, D. A. “Champions for Radical New Inventions," Harvard Business Review (41:2), 1963, pp. $77-86$.

Swanson, E. B. "Information Systems in Organization Theory: A Review," in Critical Issues in Information Systems Research, R. J. (Boland and R. A. Hirschheim (eds.). Chichester, England: Wiley \& Sons, 1987, pp. 181-204.

Walsham, G. Interpreting Information Systems in Organizations. Chichester, England: Wiley \& Sons, 1993.

Wynekoop, J. L., and Senn, J. A. "Case Implementation: The Importance of Multiple Perspectives," in Proceedings of SIGCPR, New York, Association for Computing Machinery, April 1992.

Yin, R. K. Case Study Research: Design and Methods. Newbury Park, CA: Sage Publications, 1989.

Zaltman, G.; Duncan, R.; and Holbek, J. Innovations and Organizations. New York: Wiley \& Sons, 1973.

\section{References}

Rens Scheepers is a guest researcher in Information Systems at Aalborg University, Denmark where he is currently completing his Ph.D. His present research concerns the organizational dynamics associated with the implementation of intranet technology. He is on study leave from his position as Manager, Marketing and Business Systems at the CSIR in South Africa. He holds a B.Sc. (Hons.) in Computer Science and an MBA from the University of Pretoria. His URL is http://www.cs.auc/dk/ rens and his e-mail address is rens@cs.auc.dk. 